\title{
Electrostatic beneficiation of lunar regolith: Applications in In-situ Resource Utilization
}

\author{
Steve Trigwell ${ }^{1}$, James Captain ${ }^{2}$, Kyle Weis $^{2}$, and Jacqueline Quinn ${ }^{3}$ \\ ${ }^{1}$ Sierra Lobo, ESC-24, Kennedy Space Center, FL 32899 \\ ${ }^{2}$ QinetiQ North America, ESC-15, Kennedy Space Center, FL 32899 \\ ${ }^{3}$ NASA, NE-S1, Kennedy Space Center, FL 32899
}

\begin{abstract}
Upon returning to the moon, or further afield such as Mars, presents enormous challenges in sustaining life for extended periods of time far beyond the few days the astronauts experienced on the moon during the Apollo missions. A stay on Mars is envisioned to last several months, and it would be cost prohibitive to take all the requirements for such a stay from earth. Therefore, future exploration missions will be required to be self-sufficient and utilize the resources available at the mission site to sustain human occupation. Such an exercise is currently the focus of intense research at NASA under the In-situ Resource Utilization (ISRU) program. As well as oxygen and water necessary for human life, resources for providing building materials for habitats, radiation protection, and landing/launch pads are required. All these materials can be provided by the regolith present on the surface as it contains sufficient minerals and metals oxides to meet the requirements. However, before processing, it would be cost effective if the regolith could be enriched in the mineral(s) of interest. This can be achieved by electrostatic beneficiation in which tribocharged mineral particles are separated out and the feedstock enriched or depleted as required. The results of electrostatic beneficiation of lunar simulants and actual Apollo regolith, in lunar high vacuum are reported in which various degrees of efficient particle separation and mineral enrichment up to a few hundred percent were achieved.
\end{abstract}




\section{Introduction}

Future NASA manned missions of exploration, whether back to the moon or further objectives such as Mars or asteroids, will require the astronauts to spend considerable time is a hostile environment requiring crucial life-sustaining habitats and protection. To provide the required materials to construct a base of habitats that will provide the necessary radiation and thermal protection, along with future landing and launch pads for replenishment missions, and the required oxygen and water, and bring all this from earth, would be extremely cost ineffective. It is therefore necessary to identify the materials that can be utilized at the mission sites to produce the required end products to sustain life, i.e. living off the land. This program is an area of intensive research at NASA and is collectively known as In-situ Resource Utilization (ISRU). The lunar regolith covering the surface of the moon is a product of eons of volcanic activity and micro-meteoritic bombardment, resulting in a covering of fine dust composed of minerals containing oxides of major metals such as aluminum, iron, titanium, magnesium, and sodium. Also included are oxides of elements such as silicon, calcium and potassium. These elements are present in minerals such anorthite, olivine, spodumene, ilmenite, and various feldspars and glass agglutinates. There are several processes in work to extract the oxygen from the regolith; molten oxide electrolysis (Sibille et al. 2009), the lunar water resource demonstration (Moscatello et al. 2009), etc utilizing hydrogen for reduction, resulting in oxygen and water. The residual regolith is an oxygen reduced alloy of the constituent metal elements that may provide sufficient mechanical and thermal properties for construction materials. Similarly, research is being undertaken on sintering lunar regolith to form tiles and pads for landing/launch sites (Hintze, et al. 2009), and to prevent ejecta of regolith by the rocket plumes (Metzger et al. 2009, Immer et al. 2011) that could cause significant damage to close-by habitats or structures. Whatever the 
application, building materials or water and oxygen, different concentrations of the composing elements are required, and considerable cost in time and energy would be saved if the desired minerals were more highly concentrated in the feedstock before processing. In the case of oxygen production, the mineral ilmenite $\left(\mathrm{FeTiO}_{3}\right)$ is of interest as it is more energetically favorable for extraction (Cameron 1992, Rao et al. 1979]. Ilmenite is the most abundant oxide mineral in lunar rocks (up to $20 \%$ in mare basalts), and can yield up to $10.5 \%$ oxygen by hydrogen reduction of the contained $\mathrm{FeO}$ (Berggren et al, 2011). Also the production of iron and titanium as side products is a bonus for construction materials. In this case, enrichment of the ilmenite concentration in the lunar regolith would be desirable.

Triboelectrification and electrostatic beneficiation of minerals using a parallel-plate separator is a well known technology, and has been successfully used to separate coal from minerals (Inculet et al 1982), quartz from feldspar, phosphate rock from silica sand, and phosphorus from silica and iron ore (Trigwell 2002). Actual lunar regolith is a powdery dust with a grain size range of 40 to $800 \mu \mathrm{m}$, with most falling between 45 to $100 \mu \mathrm{m}$ (Heiken et al. 1993). Figure 1 shows an image of a lunar mare soils sample containing a certain fraction of free mineral particles, including ilmenite and pyroxene. The particles in this image are approximately $50-100 \mu \mathrm{m}$ in size showing suitability for beneficiation. Lunar regolith also has a low electrical conductivity and dielectric losses, and combined with lack of moisture preventing particles from sticking together and lack of atmospheric gaseous breakdown in the lunar environment, lends itself for ideal triboelectrification and electrostatic separation (Trigwell et al. 2006, Captain et al. 2007, Trigwell et al. 2009).

In this study, the goal was to enrich the ilmenite concentration in lunar regolith for processing. For this, lunar simulants JSC-1A (Orbital Technologies Corp, Madison, WI), and NU- LHT-2M 
(US Geological Survey, Denver, CO) were used to optimize the process at high vacuum. Actual beneficiation with Apollo 1414163 lunar regolith was then performed.

\section{Experimental}

The apparatus used to perform the electrostatic beneficiation is shown in Figure 2. A vibrating feeder was used to provide a steady flow of regolith into the static charger which consisted of a series of baffles of varied materials so that the regolith would encounter many contacts with the charger material as it passed through the mixer by gravity. The materials used for the different experiments were aluminum, copper, and polytetrafluorethylene (PTFE), with work functions of $4.28 \mathrm{eV}, 4.65 \mathrm{eV}$, and $5.75 \mathrm{eV}$, respectively (Trigwell 2002). The regolith contains mineral particles of different compositions that will tribocharge when in contact with a different material. Different particles will therefore charge up with different polarities and quantity of charge, depending upon the work function difference between the mineral and the contacting material. The regolith then fell into the separator chamber between two copper plates at voltages of up $+/-$ $30 \mathrm{kV}$. Particles were deflected towards one plate or the other depending upon the quantity and polarity of the charge acquired during the tribocharging and the strength of the electric field (Figure 3). The apparatus was designed for use in a vacuum chamber so that testing and optimization were performed at $1 \times 10^{-6}$ mbar. For vacuum testing, the regolith was pre-dried in a thermal vacuum oven so it was as dry as possible before tribocharging.

In order to test the viability of the beneficiation apparatus, a test mixture was made up, composed of the minerals representing those found in the lunar regolith, namely; feldspar $\left.(\mathrm{Na}, \mathrm{K}, \mathrm{Ca}) \mathrm{AlSi}_{3} \mathrm{O}_{8} ; \mathrm{SiO}_{2}\right)$, spodumene $\left[\mathrm{LiAl}\left(\mathrm{Si}_{2} \mathrm{O}_{6}\right)\right]$ - pyroxene group, olivine $\left.(\mathrm{Mg}, \mathrm{Fe})_{2} \mathrm{SiO}_{4}\right)$, and ilmenite $\left(\mathrm{FeTiO}_{3}\right)$ (Reade Advanced materials, $\left.\mathrm{RI}\right)$. A summary of compositions of lunar regolith from the literature show the major minerals present as plagioclase; $20-50 \mathrm{wt} \%$, 
pyroxene; $40-65 \mathrm{wt} \%$, olivine; $2-15 \mathrm{wt} \%$, and ilmenite; $2-15 \mathrm{wt} \%$. A mixture was made up in a weight ratio of 4:4:1:1 of feldspar, spodumene, olivine, and ilmenite. This is the same ratio as that reported by Agosta $(1984,1985)$ who achieved successful separation of ilmenite from a mixture of anorthite (feldspar group), augite (pyroxene group), olivine, and ilmenite in vacuum. After optimization of the beneficiator, lunar simulants JSC-1A and NU-LHT-2M, and finally, Apollo 1414163 lunar regolith were tested.

The particles were collected in a tray at the bottom of the separator that was split into 3 or 7 bins (the 7 bin version is shown in Figure 3), and analyzed for composition by X-ray photoelectron Spectroscopy (XPS). For the matrix and number of samples analyzed, this technique was considered efficient enough to allow for quick turnaround of samples and provide statistically valid data (Trigwell et al. 2011). The compositions were compared to those taken for control preseparated samples.

The XPS analyses were performed on a Thermo Scientific K-Alpha X-ray spectrometer, using a $\mathrm{Al} \mathrm{K} \alpha$ source at $1486.6 \mathrm{eV}$ at a background pressure of $2 \times 10^{-9} \mathrm{mbar}$. Ten samples of each separated fraction were analyzed using a $400 \mu \mathrm{m}$ spot size to encompass as many grains as possible. The collected data were referenced to the C1s peak to $284.6 \mathrm{eV}$. Quantification was performed by measuring the areas under the peaks of the detected elements in the XPS spectrum, and normalizing using sensitivity factors supplied by the instrument manufacturer to produce relative atomic $\%$ concentrations. The sensitivity factors are a function of the ionization crosssection and the escape depth of the photoelectrons for the elements. The escape depth of the photoelectrons is in the order of 50-100 $\AA$, and so XPS is a very surface sensitive technique. Considering that tribocharging of the particles takes place in the surface region, optimization of beneficiation is dependent upon surface composition. Due to the fact that the simulants and 
Apollo 14 regolith had been exposed to ambient, and in the case of the simulants, handled is an assortment of conditions, quantification was normalized without the carbon peak contribution.

\section{Results and Discussion}

\section{Test lunar mixture}

Separated lunar mixture samples were collected from each of the 7 bins at the bottom of the separator after passing through an electric field with the plates at $+/-15 \mathrm{kV}$, and analyzed by XPS. The data was then compared to XPS analysis of the mixture before separation, and the data was reported as a percentage increase or decrease in relative concentrations in Figure 4. Only the major elements are presented to clarify the plot. From this data, it can be clearly seen that the Fe and Ti concentrations are significantly higher in bins 3 and 4, while a significant increase in the $\mathrm{Ca}$ and $\mathrm{Mg}$ concentrations was observed towards the left hand negative plate. From the known compositions of the minerals used in the test mixture, the spodumene and olivine are more concentrated towards the negative plate, and the ilmenite more in the middle indicating it did not acquire as high a charge and so was not deflected as much. The feldspar and spodumene powders were an off-white color, the olivine was greenish-white, and the ilmenite was distinctively dark grey. When mixed, the result was a light grey powder. In Figure 5, the as-made mixture is shown

on the left, and after separation, the $1^{\text {st }}$ bin (left paper) is a much lighter, and bin 7 (right paper) is also lighter, while the dark gray of the ilmenite is obviously seen between the two in bin 3 , showing an obvious correlation with the XPS data. The results here on the mineral mixture showed significant enrichment separation of the individual mineral compositions after beneficiation and proof of concept.

JSC-1A lunar simulant 
Previous experiments had been performed by XPS (Trigwell, 2009) to determine if there was a compositional variation as a function of particle size in JSC-1A. Little compositional variation was observed between sieved size fractions of JSC-1A, and so the $50-75 \mu \mathrm{m}$ size fraction was used as this is near the center of the majority of the lunar regolith size range of $45-100 \mu \mathrm{m}$ (Heiken et al, 1993, Inculet and Criswell 1979). The simulant was run through the separator with the plates at $+/-15 \mathrm{kV}$. In these experiments, only 3 bins were used to collect the separated regolith fractions, one under the positive plate, one under the negative plate, and everything else was collected in the middle labeled bottom tray. This was to limit the large matrix of samples that would have been collected while optimizing the separator if 7 bins were used. Table 1 shows the XPS beneficiation data for the JSC-1A simulant as a function of charger material. The first observations are that the separation concentrations are not as dramatic as for the test mineral mixture. This was to be expected as although ilmenite has been reported by x-ray diffraction analysis to be present in JSC-1A (Ray et al, 2010), it was reported to be at a very low concentration of 0.1 molar \% when analyzed by SEM/EDS (Schrader et al, 2010). However, Shrader et al (2010) also report the Fe and $\mathrm{Ti}$ are present as Ti-magnetite rather than ilmenite. There are some distinct differences in the $\mathrm{Fe}$ and $\mathrm{Ti}$ concentrations between the separated fractions for all three types of chargers above the $5 \%$ error that indicated some degree of separation of minerals. The most significant changes being for the $\mathrm{Na}$ concentrations for the $\mathrm{Cu}$ and PTFE chargers which may show the presence of the different plagioclase phases. NU-LHT-2M lunar simulant NU-LHT-2M is a newer simulant representing the highland regions on the moon, developed to help in the development of regolith-moving machines and vehicles to be used in future lunar missions (Zeng et al, 2010). However, although it does contain ilmenite, the concentration is still 
low (0.2 molar \%, Schrader et al, 2010). Due to this low concentration, and subsequent uncertainty of quantification of beneficiated regolith, $5 \%$ by weight of ilmenite was added to the NU-LHT-2M. Separation runs for unsieved NU-LHT-2M were also performed for comparison. Again as for the JSC-1A, due to the large number of runs performed, only 3 bins were used to collect the separated fractions. The results are summarized in Table 2. In these results, enrichment in Fe and $\mathrm{Ti}$ were clearly observed in the bottom tray for both the unsieved and 75$100 \mu \mathrm{m}$ size fraction. This was a similar result to that for the test mixture in which the ilmenite was observed to be enriched in the center bins rather than towards the positive or negative plate. From both the unseived feedstock and the $75-100 \mu \mathrm{m}$ size fraction, samples from the bottom tray showing the highest increase in Fe and Ti concentrations, were submitted to the Johnson Space Center for water production from the regolith. The elemental compositions by XPS and the corresponding amount of water produced from these samples are presented in Table 3 where Run A and Run B represent the two runs that were performed for the water production. For the original unsieved feedstock and the $75-100 \mu \mathrm{m}$ feedstock, $65-70 \mathrm{mg}$ of water was generated. It was observed that this rose significantly for the Fe and Ti enriched separated fractions. The highest amount of water generated (192 mg) was from the highest Ti enriched fraction of the 75$100 \mu \mathrm{m}$ size range. In this case, no significant increase in the Fe concentration was observed which is interesting as oxygen recovery for water generation from lunar regolith is generally considered to come from the iron oxides present in the regolith (Berggren et al, 2011, Allen et al, 1994). However, the increase in the $\mathrm{Na}$ and $\mathrm{Al}$, indicating an enrichment of the plagioclase, may have contributed.

Apollo 1414163 lunar regolith 
The Apollo 14 regolith contains about 1.3 vol.\% of ilmenite which is low compared to the Apollo 11 (6.5 vol.\%) and Apollo 17 highland regolith (12.8 vol.\%) (Heiken et al, 1993). Due to the small quantity of Apollo 14 regolith available, the testing was limited to the sieved 50-75 $\mu \mathrm{m}$ size range. The beneficiation was optimized at $+/-15 \mathrm{kV}$ applied to the plates of the separator using an $\mathrm{Al}$ charger and the separated fractions were collected in 3 bins. Three separate runs were performed and the mean values for the elemental relative compositions of the separated fractions were calculated. The results are summarized in Table 4. As observed in table 4, the bottom tray showed the highest increase in both Fe and Ti concentrations compared to the original regolith composition. This data shows remarkable consistency with that of the test mixture and the NU-LHT-2M beneficiation results in that the Ti containing mineral tends not to be charged and falls through straight through the separator after tribocharging, and that the other minerals present acquire higher charge, both positive and negative, and are deflected towards the plates. As for the NU-LHT-2M simulant, the increase in the Ti concentration was significantly higher than for the Fe.

\section{Future work}

Other work (Berggren et al., 2011, Taylor et al 1992) have shown success using magnetic separation due to the magnetic susceptibility of lunar regolith. Also, particle size plays an important part. The research in this study showed tribocharging and electrostatic beneficiation performed optimally with a particle size around 50-100 $\mu \mathrm{m}$. Smaller particles were found to charge up significantly and stick to the chargers and walls, inhibiting regolith flow and preventing other particles from impacting the chargers. However, it is yet to be determined if a fine grain concentrate would be preferred for processing. Therefore optimization of the beneficiation technique utilizing particle sizing and magnetic separation components are being 
examined. Studies are also planned on performing multiple passes of the most enriched fraction from each pass to determine the ultimate feedstock enrichment.

Further studies were also undertaken performing the beneficiation experiments using the NULHT-2M simulant in a reduced gravity environment $(1 / 6 \mathrm{~g})$, and are the subject of a second paper.

\section{Conclusions}

Electrostatic beneficiation was demonstrated to enhance the desired mineral concentrates, i.e. iron oxides and ilmenite, in single pass separation tests in vacuum using a test mixture and simulant NU-LHT-2M. Simulant JSC-1A was not that successful, but was due to its lack of ilmenite and that it did not contain individual separate mineral particles. The results were particularly encouraging for the Apollo 14 regolith.

These results indicate that tribocharging under a gravity feed, flowed by a twin-plate charge separator is a viable method for enrichment of lunar regolith for ISRU processing.

\section{References}

Agosta, W.M. (1984). "Electrostatic separation and sizing of ilmenite in lunar soil simulants and samples”. Proc. Lunar Planetary Sci. XV, Houston, TX. 1-2.'

Agosta, W.M. (1985). "Electrostatic concentration of lunar soil minerals", in Lunar Bases and Space Activities of the $21^{\text {st }}$ Century, W.W. mendall, Ed. Houston, TX, Lunar Planetary Inst. 453464.

Allen, C.C., Bond, G.G., McKay, D.S. (1994). "Lunar oxygen production - A maturing technology". Engineering, Construction, and Operations in Space IV, ASME, 1157-1166 Berggren, M., Zubrin, R., Jonscher, P., and Kilgore, J. (2011). "Lunar soil particle separator", Proc. 49 $9^{\text {th }}$ AIAA Aerospace Sciences Meeting, Orlando, FL. AIAA 2011-436. 
Cameron, E.N. (1992). “Apollo 11 Ilmenite revisited”. Space 92, The 3rd International Conference on Engineering, Construction, and Operations in Space. Denver, CO. WCSAR-TRAR3-9201-3.

Captain, J.G., Trigwell, S., Arens, E.E., Biris, A.S., Captain, J.E., Quinn, J.W., and Calle, C.I. (2007). "Tribocharging Lunar Simulant in Vacuum for Electrostatic Beneficiation", AIP Conf. Proc., 880, STAIF 2007, Albuquerque, NM, 951-956.

Heiken, G.H., Vaniman, D.T., and B.M. French, B.M. (Eds.). (1993). Lunar Source Book: A user's guide to the moon, UK: Cambridge University Press.

Hintze, P.E., Curran, J., and Back, T. (2009). "Lunar Surface Stabilization via Sintering or the use of Heat Cured Polymers," Proc. $47^{\text {th }}$ AIAA Aerospace Sciences Meeting, Orlando, FL. AIAA 2009-1015

Immer, C.D., Metzger, P.T., Nick, A., and Horan, R. (2011). “Apollo 12 lunar module exhaust plume impingement on lunar Surveyor III", Icarus, 211(2), 1089-1102.

Inculet, I.I., Bergougnou, M.A., and Brown, J.D. (1982). "Physical Cleaning of Coal - Present and Developing Methods”, Y.A. Liu [Ed.], Marcel Dekker, New York, Inculet, I.I., and Criswell, D.R. (1979). "Electrostatic benefication of ores on the moon surface", Inst. Phys. Conf. Series., 48, 45-53.

Metzger P.T., Li, X., Immer, C.D., and Lane, J. (2009). "ISRU implications of lunar and Martian plume effects", Proc. $47^{\text {th }}$ AIAA Aerospace Sciences Conference, Orlando, FL, AIAA 20091204.

Moscatello, A.C., Captain, J.E., Quinn, J.W., Gibson, T.L., Perusich, S.A., and Weis, K.H. (2009). "Lunar Water Demonstration (LWRD) Test Results", Proc. AIAA SPACE 2009 Conference and Exposition, Pasadena, CA. AIAA 2009-6474. 
Rao, D.B., Choudary, U.V., Erstfeld, T.E., Williams, R.J., and Chang, Y.A., (1979). "Extraction Processes for the Production of Aluminum, Titanium, Iron, Magnesium, and Oxygen from Nonterrestrial Materials". Space Resources and Space Settlements, NASA SP-428, pp. 257-274.

Ray, C.S., Reis, S.T., Sen, S., and O’Dell, J.S. (2010). “JSC-1A lunar soil simulant:

Characterization, glass formation, and selected glass properties". Journal of Non-Crystalline Solids, 356, 2369-2374.

Schrader, C.M., Rickman, D.L., McLemore, C.A., and Fikes, J.C. (2010). "Lunar regolith simulant user's guide”. NASA Technical Memorandom, NASA/TM-2010-216446.

Sibille, L., Sadoway, D.R., Sirk, A., Tripathy, P., Melendez, O., Standish, E., Dominguez, J.A., Stefanescu, D.M., Curreri, P.A., and Poizeau, S. (2009). "Recent Advances in Scale-up Development of Molten Regolith Electrolysis for Oxygen Production in support of a Lunar Base", Proc. 47 $7^{\text {th }}$ AIAA Aerospace Sciences Meeting, Orlando, FL, AIAA 2009-659. Taylor, A.T., Patchen, A., Taylor, D-H.S., Chambers, J.G., and McKay, D.S. (1996). "X-ray digital imaging petrography of lunar mare soils: Modal analysis of minerals and glasses", Icarus, 124(2), 500-512.

Trigwell, S., Captain, J.G., Arens, E.E., Quinn, J.W., and Calle, C.I. (2009). The use of Tribocharging in the Electrostatic Beneficiation of Lunar Simulant”. IEEE Trans. Ind. Apps., 45(3), 1060-1067.

Trigwell, S., Captain, J.G., Captain, J.E., Arens, E.E., Quinn, J.W., and Calle, C.I. (2006). "Electrostatic Beneficiation of Lunar Simulant", Proc. ESA/IEJ/IEEE-IAS Joint Conference, UC Berkeley, CA, 297-306.

Trigwell, S. (2002). "Correlation between Surface Structure and Tribocharging of Powders", PhD Dissertation, University of Arkansas at Little Rock, Little Roc, AR. 
Trigwell, S., Lane, J., Captain J.G., Weis K., Quinn, J.W., and Watanabe, F. (2011).

"Quantification of Efficiency of Beneficiation of Lunar Regolith", to be submitted to Particulate Science and Technology.

Zeng, X., He. H., and Wilkinson, A. (2010). "Geotechnical properties of NU-LHT-2M lunar highland simulant”, Journal of Aerospace Engineering, 23(4), 213-218.

Zhao, Y., and Shadman, F. (1993). "Production of oxygen from lunar ilmenite". In Resources of Near Earth Space, J. Lewis, M.S. Mathews, and M.L. Guerrier, eds., University of Arizona Press, AZ. 149-178. 


\section{Figure captions}

Figure 1. Lunar mare soil sample showing distribution of free mineral particles.

Figure 2. Electrostatic beneficiation apparatus.

Figure 3. Schematic of the separator. The regolith particles fall through the chamber under the

force of gravity, $\mathrm{F}_{\mathrm{g}}=\mathrm{mg}$, but are deflected by the force due to the electric field (E) and charge on the particle $(\mathrm{q}), \mathrm{F}_{\mathrm{E}}=\mathrm{qE}$.

Figure 4. Distribution of elemental compositions within the bins after beneficiation using a test mineral mixture.

Figure 5. Distribution of separated fractions from the test mineral mixture after passing through the electrostatic separator. 


\section{Table Captions}

Table 1. JSC-1A simulant results. Elemental compositions are shown as relative percent increase or decrease from original mixture after beneficiation.

Table 2. NU-LHT-2M simulant results. Elemental compositions are shown as relative percent increase or decrease from original mixture after beneficiation.

Table 3. NU-LHT-2M simulant. Elemental compositions are shown as relative percent increase or decrease from original mixture after beneficiation for samples used in water extraction.

Table 4. Apollo 1414163 results. Elemental compositions are shown as relative percent increase or decrease from original mixture after beneficiation. 


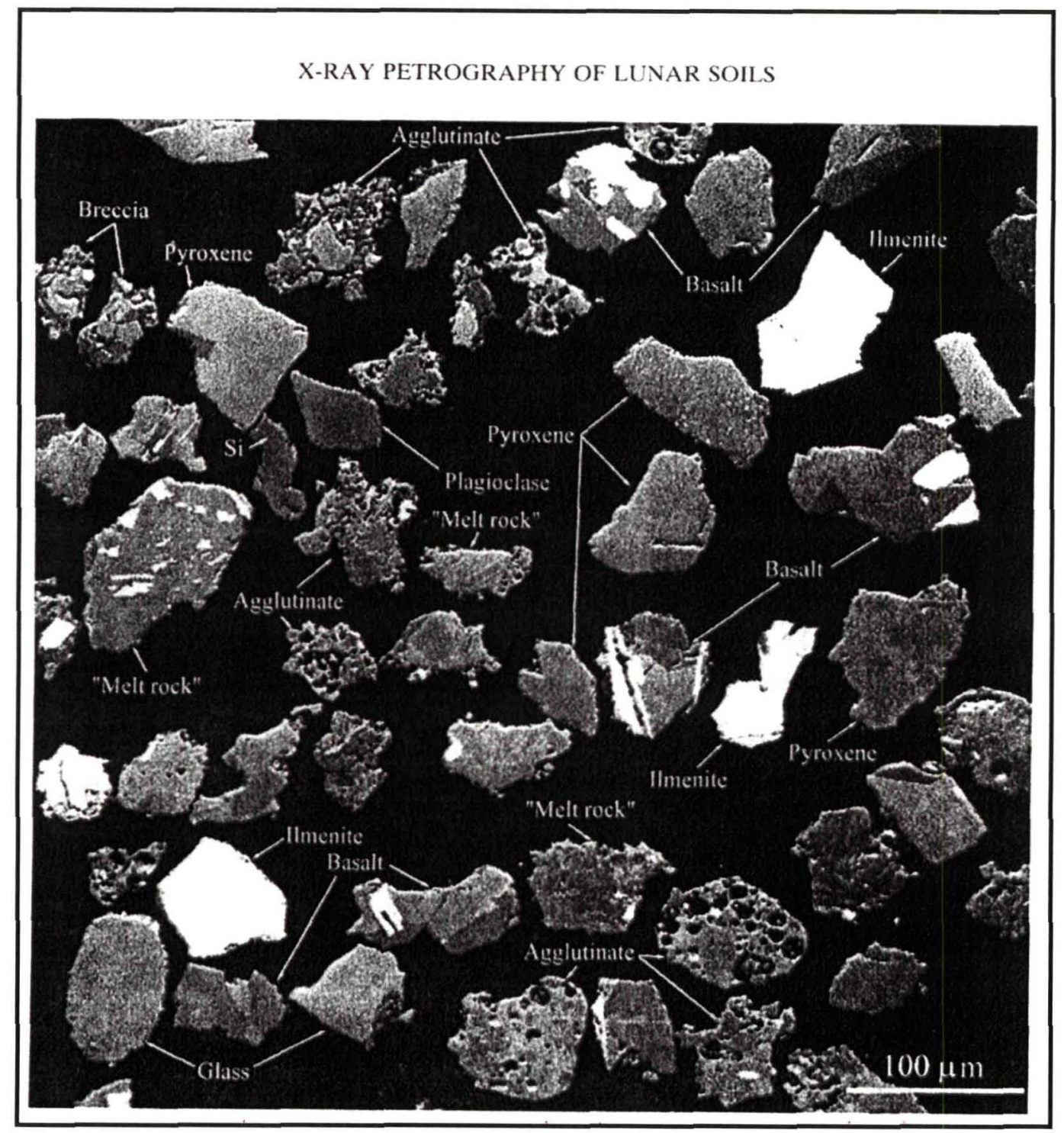

Fig. 1 


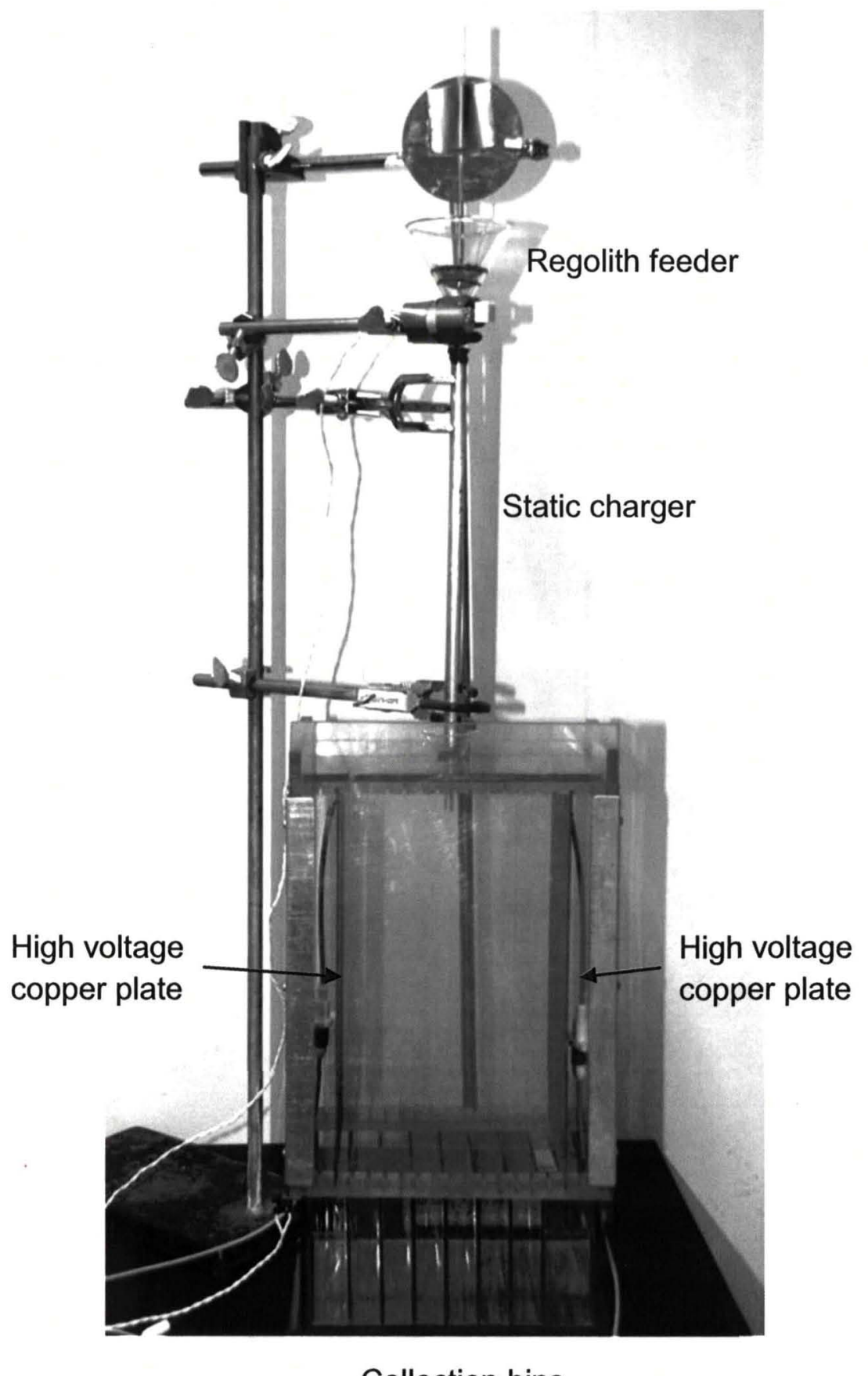

Collection bins

Fig. 2 


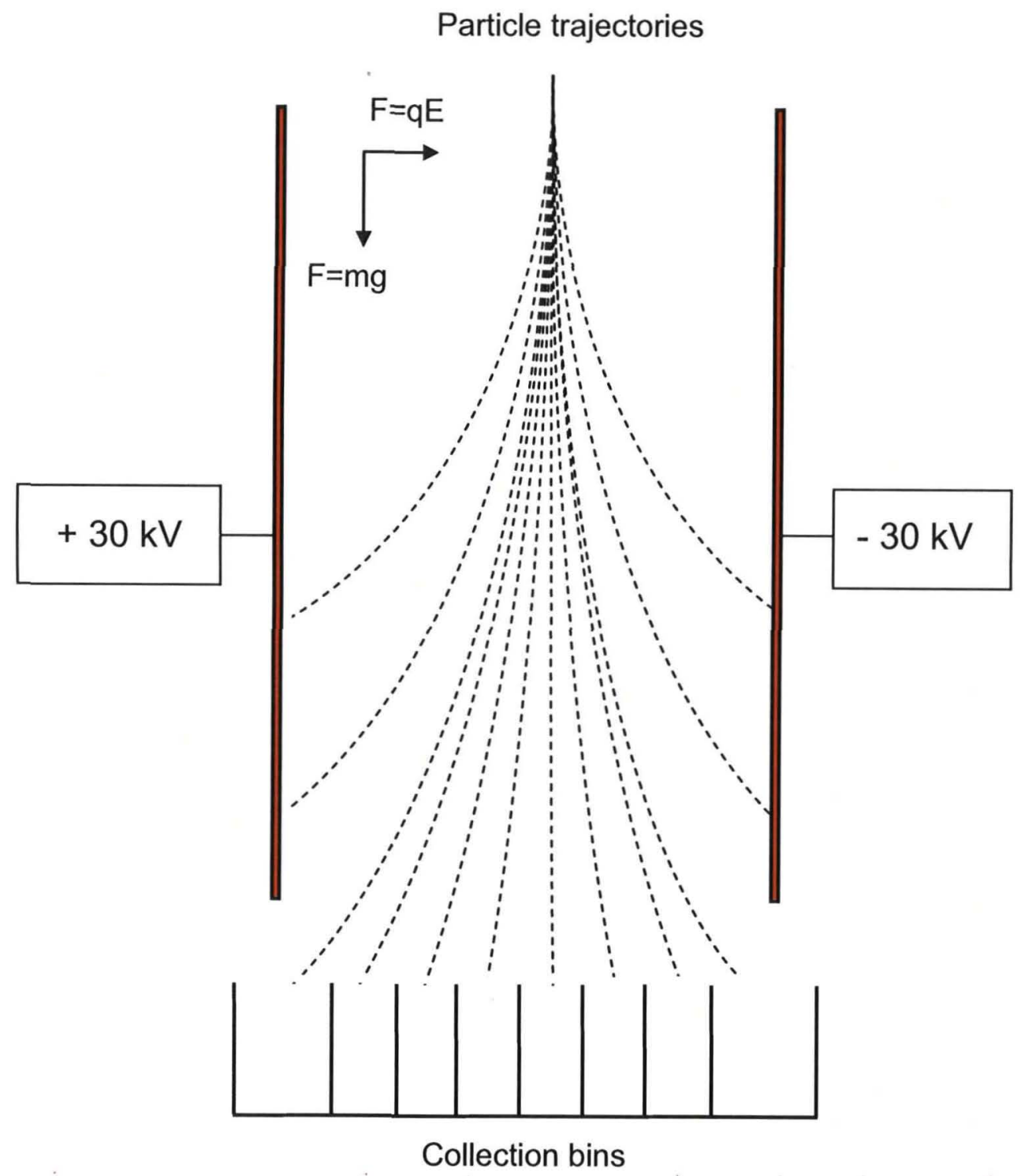

Fig. 3 


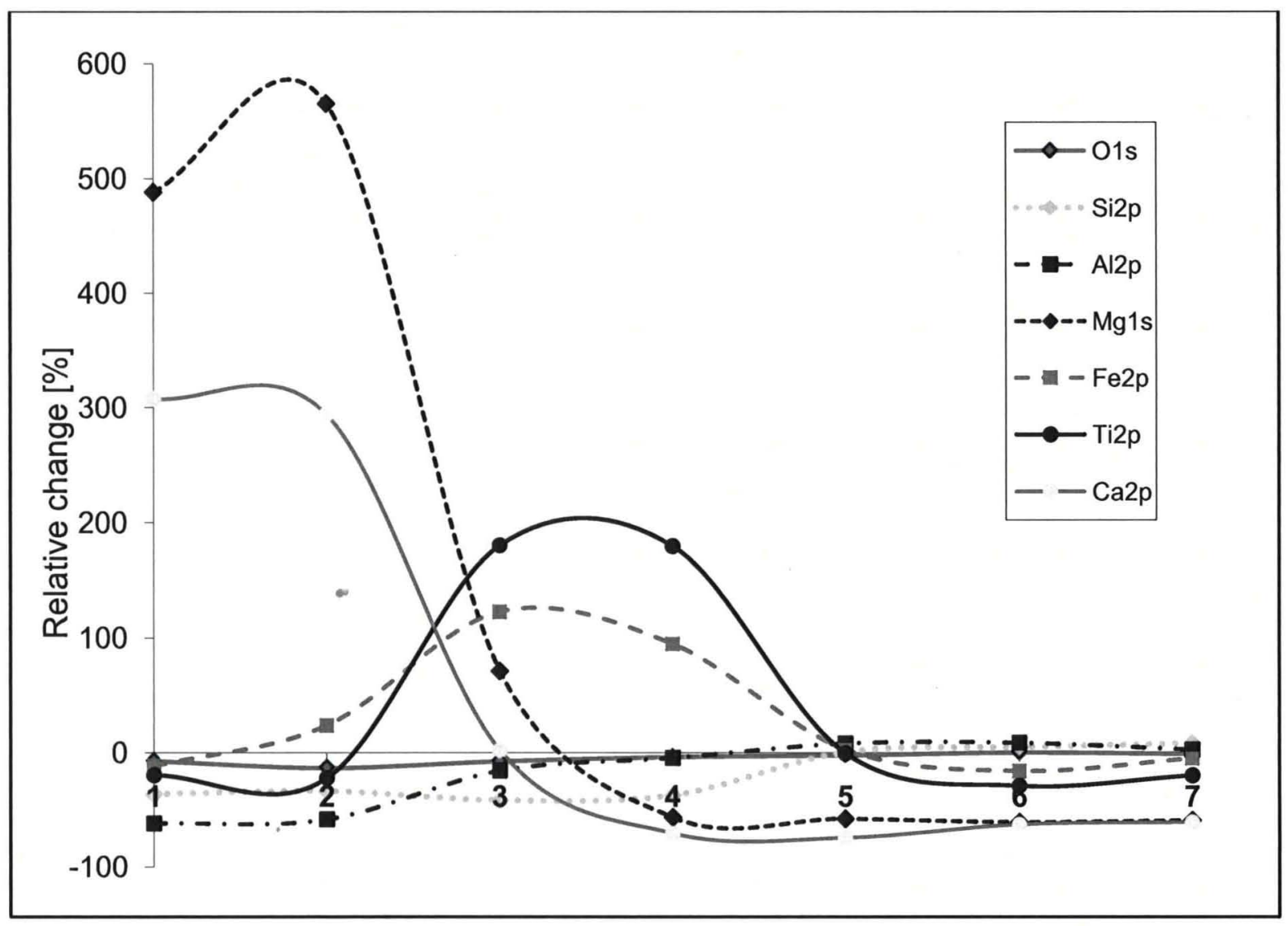

Fig .4 


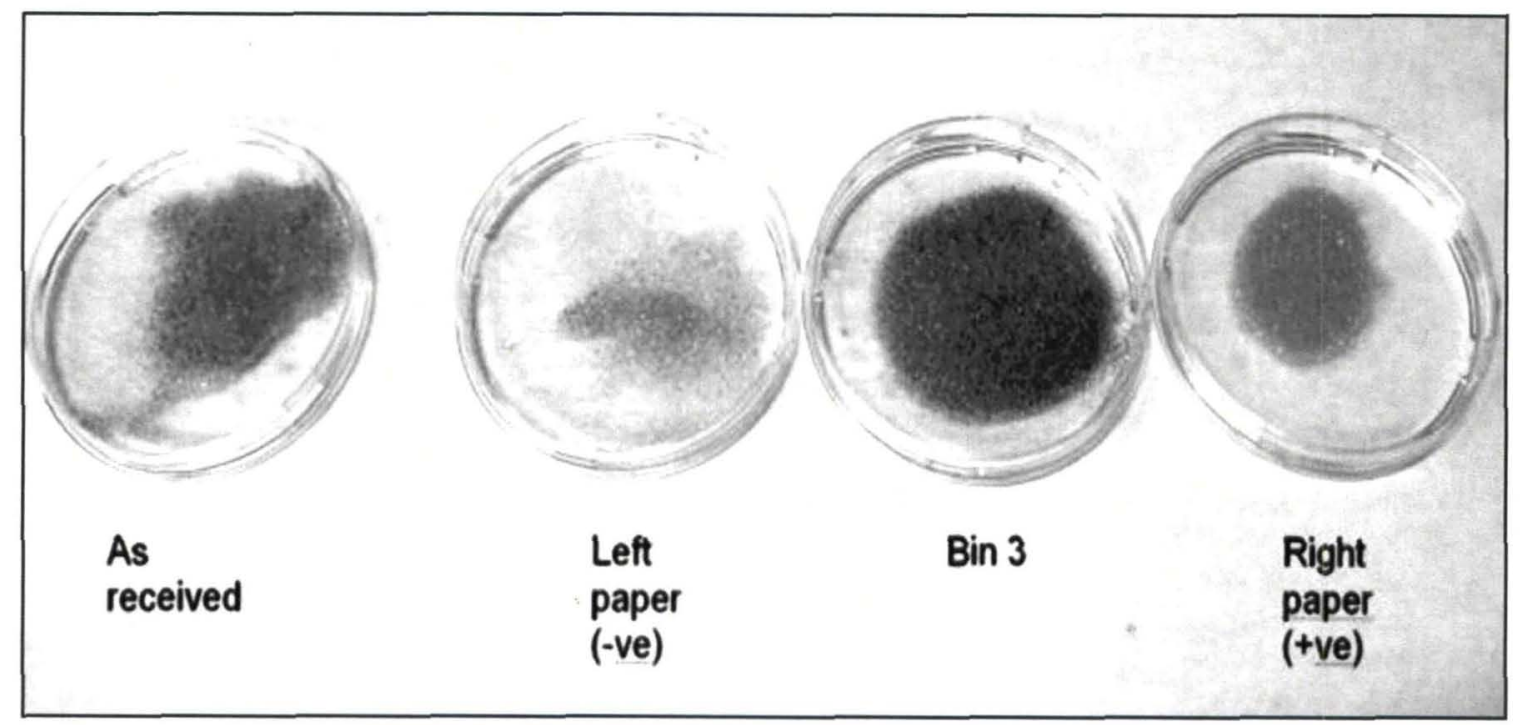

Fig. 5 
Table 1.

\begin{tabular}{l|l|cccccccc}
\hline Charger & $\begin{array}{l}\text { Separated } \\
\text { fraction }\end{array}$ & $\mathbf{O}$ & $\mathbf{C}$ & $\mathbf{S i}$ & $\mathbf{A l}$ & $\mathbf{N a}$ & $\mathbf{F e}$ & $\mathbf{T i}$ & $\mathbf{C a}$ \\
\hline $\mathbf{A l}$ & + ve plate & - & - & - & - & $-11 \%$ & $+7 \%$ & - & $-7 \%$ \\
& $\begin{array}{l}\text {-ve plate } \\
\text { Bottom } \\
\text { tray }\end{array}$ & - & $+16 \%$ & - & - & - & - & $-12 \%$ & - \\
\hline $\mathbf{C u}$ & $\begin{array}{l}\text { +ve plate } \\
\text {-ve plate }\end{array}$ & - & - & - & - & - & - & $-12 \%$ & - \\
\hline PTFE & $\begin{array}{l}\text { Bottom } \\
\text { tray }\end{array}$ & - & $-10 \%$ & - & - & - & $+7 \%$ & $+25 \%$ & - \\
\hline $\begin{array}{l}\text { +ve plate } \\
\text {-ve plate }\end{array}$ & - & - & - & $+9 \%$ & $-15 \%$ & $-6 \%$ & $-25 \%$ & $-7 \%$ \\
& $\begin{array}{l}\text { Bottom } \\
\text { tray }\end{array}$ & - & - & - & - & $-11 \%$ & - & $-12 \%$ & - \\
& & $-15 \%$ & - & - & $+18 \%$ & - & - & - \\
\hline
\end{tabular}


Table 2.

\begin{tabular}{c|cccccccc}
\hline All sizes & $\mathbf{M g}$ & $\mathbf{N a}$ & $\mathbf{F e}$ & $\mathbf{O}$ & $\mathbf{T i}$ & $\mathbf{C a}$ & $\mathbf{S i}$ & $\mathbf{A l}$ \\
\hline +ve plate & $+5 \%$ & $+22 \%$ & - & - & $-11 \%$ & - & - & - \\
-ve plate & - & $+6 \%$ & - & - & $-12 \%$ & - & - & $-6 \%$ \\
Bottom tray & - & $+8 \%$ & $+33 \%$ & - & $+67 \%$ & - & - & - \\
\hline $\mathbf{7 5 - 1 0 0 \mu m}$ & & & & & & & & \\
\hline +ve plate & - & $+10 \%$ & $-7 \%$ & - & $-15 \%$ & - & - & $+5 \%$ \\
-ve plate & $-7 \%$ & $+10 \%$ & $-7 \%$ & - & $-36 \%$ & $+5 \%$ & - & $+5 \%$ \\
Bottom tray & - & - & $+6 \%$ & - & $+31 \%$ & - & - & $+6 \%$ \\
\hline
\end{tabular}


Table 3 .

\begin{tabular}{l|cccccccc|cc}
\hline & Mg & Na & Fe & O & Ti & Ca & Si & Al & $\begin{array}{c}\text { RunA } \\
{[\mathbf{m g}]}\end{array}$ & $\begin{array}{c}\text { RunB } \\
{[\mathbf{m g}]}\end{array}$ \\
\hline $\begin{array}{l}\text { Unseived feedstock } \\
\text { Run } 2 \text { bottom }\end{array}$ & - & - & - & - & - & - & - & - & 65 & 70 \\
$\begin{array}{l}75-100 \mu \mathrm{m} \\
\text { feedstock }\end{array}$ & $+5 \%$ & - & $+9 \%$ & - & $+5 \%$ & - & - & - & 128 & 120 \\
$75-100 \mu \mathrm{m}$ run 1 & - & - & - & - & - & - & - & - & 70 & - \\
$\begin{array}{l}\text { bottom } \\
75-100 \mu \mathrm{m} \text { run 2 } \\
\text { bottom }\end{array}$ & - & - & $+6 \%$ & - & $+31 \%$ & - & - & $+6 \%$ & 116 & 100 \\
\hline
\end{tabular}


Table 4.

\begin{tabular}{c|ccccccc}
\hline Sample & Na & Fe & $\mathbf{O}$ & $\mathbf{T i}$ & $\mathbf{C a}$ & $\mathbf{S i}$ & $\mathbf{A l}$ \\
\hline +ve plate & $+15 \%$ & $+7 \%$ & - & $+57 \%$ & - & - & $-8 \%$ \\
-ve plate & $+10 \%$ & $-5 \%$ & - & $-11 \%$ & - & - & - \\
Bottom tray & $-16 \%$ & $+12 \%$ & - & $+164 \%$ & - & - & - \\
\hline
\end{tabular}

